\title{
Verification of the Comparability of Laboratory Results from Two Instruments within One Health Care System According to Clinical and Laboratory Standard Institute EP31-A-IR
}

Eun Jin Lee, Eunyup Lee, Miyoung Kim, Han-Sung Kim, Young Kyung Lee, and Hee Jung Kang

Department of Laboratory Medicine, Hallym University Sacred Heart Hospital, Hallym University College of Medicine, Anyang, Korea

Corresponding author: Hee Jung Kang Department of Laboratory Medicine, Hallym University Sacred Heart Hospital, Hallym University College of Medicine, 22 Gwanpyeong-ro 170beongil, Dongan-gu, Anyang 14068, Korea

Tel: $+82-31-380-3929$

Fax: +82-31-380-3934

E-mail: kangheejung@hallym. ac.kr

\begin{abstract}
Background: For convenience, multiple instruments can be used to measure the same laboratory results within one health care system. However, the laboratory must verify the comparability of the results. In this study, we evaluated a method for verifying the comparability of patient results obtained from two instruments within one health care system, EP31-A-IR, proposed by the Clinical and Laboratory Standards Institute.

Methods: Using the range test proposed by the EP31-A-IR, we evaluated the comparability of 17 clinical chemistry test results from the HITACHII/MODULAR system (Roche Diagnostics, Switzerland) and the TOSHIBA/200FR system (Toshiba Medical Systems Co., Japan). The $0.33 \times$ biological variability, allowable total error, and standards of the Clinical Laboratory Improvement Amendments were used to determine the acceptance criteria.

Results: Among 16 test parameters, the differences of means between the two instruments were less than their range rejection limit in 15 tests, and so the comparability between the two instruments was considered acceptable. Creatinine was not evaluated using this protocol because its range rejection limit was not deducible from the EP31-A-IR statistics table.

Conclusions: The EP31-A-IR guideline is useful for verifying the comparability of results between two instruments. However, not all parameters are covered by the guideline. With consideration of the characteristics of each test parameter, each laboratory should devise its own method for evaluating comparability.
\end{abstract}

(J Lab Med Qual Assur 2016;38:129-136)

Key Words: Comparability, Quality control, Range test

\section{서론}

단일 의료기관 내에서도 여러 대의 검사장비로 동일한 검사 를 시행하는 경우가 흔하다. 한정된 검체 처리량을 극복하고 더욱 신속한 검사결과를 얻기 위해 추가적으로 장비를 사용하 거나 진료의 편의를 위해 응급실이나 수술실 등에서 현장검사
를 시행하는 등의 다양한 형태로 동일한 검사를 수행하게 된 다. 그러나 서로 다른 장비에서 나타나는 측정값은 상이한 장 비 간 측정방법, 보정이나 비정밀도 등의 차이에 의하여 동등 하지 않은 결과를 보일 수 있다[1]. 이러한 검사결과의 차이는 진단과 치료에 중대한 영향을 미칠 수 있기 때문에 검사실에서 는 각각의 검사항목에서 서로 다른 장비를 이용해 측정된 검 


\section{Journal of LABORATORY MEDICINE and QUALITY ASSURANCE}

Eun Jin Lee et al $\bullet$ Verification of Comparability of Laboratory Results

사 값이 동등함을 검증하여 보고하는 것이 중요하다. 최근에 Clinical and Laboratory Standards Institute (CLSI)는 단 일 의료기관 내에서 정량검사결과들의 비교검증방법에 대한 지침을 발간하여 환자 검체를 이용한 검사방법 간 결과의 동등 성 검증을 위한 가이드라인을 제시하고 있다[1]. 이 방법은 최 대 10 개의 장비 간 동등성을 검증할 수 있으며 정도관리 데이 터를 이용하여 간편하게 수행할 수 있도록 고안되었다. 이 동 등성 검증은 (1) 주기적 검증을 위해서, (2) 보정시약 제품번 호와 시약제품번호가 변경될 때, (3) 보정과 문제해결(또는 동 등성에 관한 문제가 해결된 이후 추적관찰) 등의 목적으로 광 범위하게 이용될 수 있다.

이에 본 연구에서는 한 의료기관 임상화학검사실에서 실제 로 이용 중인 서로 다른 두 대의 장비에서 측정된 검사결과 간 동등성을 CLSI EP31-A-IR에서 제시한 동등성 평가지침을 활용하여 항목별로 검증하고 그 경험을 공유해 보고자 한다.

\section{재료 및 방법}

\section{1. 분석장비}

진단검사의학과에서 임상화학검사에 이용하고 있는 자
동화검사기기인 HITACHII/MODULAR system (Roche Diagnostics, Basel, Switzerland)과 TOSHIBA/200FR system (Toshiba Medical Systems Co., Tokyo, Japan)에서 얻어진 결과 간의 동등성을 평가하였다.

\section{2. 검증항목}

알부민(albumin), 알칼리인산분해효소(alkaline phosphatase), 알라닌아미노전달효소(alanine transaminase), 아 스파르테이트아미노전달효소(aspartate aminotransferase), 칼슘(calcium), 콜레스테롤(cholesterol), 염소(chloride), 크 레아티닌(creatinine), 직접빌리루빈(direct bilirubin), 감 마글루타밀전이효소(gamma-glutamyltranspeptidase), 포 도당(glucose), 칼륨(potassium), 젖산탈수소효소(lactate dehydrogenase), 나트륨(sodium), 단백질(protein), 총 빌리 루빈(total bilirubin), 요산(uric acid)의 17항목에 대하여 검 증하였다.

\section{3. 동등성 검증}

이 연구는 한림대학교 임상연구심사위원회/기관생명윤리 위원회로부터 심의 면제(2016-I057)를 승인받았으며 CLSI

Table 1. QC data of chemistry parameters using MODULAR and 200FR: pooled mean, SR, ST, and analyte concentration for the comparability test

\begin{tabular}{lcccc}
\hline \multicolumn{1}{c}{ Parameters } & Pooled mean & SR & ST & Analyte concentration \\
\hline Albumin (g/dL) & 4.57 & 0.06 & 0.07 & $3.7-5.5$ \\
Alkaline phosphatase (IU/L) & 59.64 & 0.88 & 0.99 & $47.7-71.6$ \\
Alanine transaminase (IU/L) & 13.85 & 0.48 & 0.63 & $11.1-16.6$ \\
Aspartate aminotransferase (IU/L) & 20.71 & 0.92 & 1.3 & $16.6-24.9$ \\
Calcium (mg/dL) & 9.44 & 0.11 & 0.16 & $7.6-11.3$ \\
Cholesterol (mg/dL) & 183.8 & 2.23 & 2.8 & $147.0-220.6$ \\
Chloride (mg/dL) & 103.5 & 0.72 & 0.81 & $82.8-124.2$ \\
Creatinine (mg/dL) & 0.79 & 0.03 & 0.08 & $0.63-0.95$ \\
Direct bilirubin (mg/dL) & 0.23 & 0.01 & 0.01 & 1.35 \\
Gamma-glutamyltranspeptidase (IU/L) & 20.88 & 0.81 & 1.42 & $16.7-25.1$ \\
Glucose (mg/dL) & 92.40 & 1.18 & $73.9-110.9$ \\
Potassium (mg/dL) & 4.35 & 0.04 & 0.05 & $3.5-5.2$ \\
Lactate dehydrogenase (IU/L) & 301.75 & 9.82 & 13.09 & $241.4-362.1$ \\
Sodium (mg/dL) & 143.01 & 0.73 & 0.89 & $114.4-171.6$ \\
Total protein (mg/dL) & 7.52 & 0.17 & 0.07 & $6.0-9.0$ \\
Total bilirubin (mg/dL) & 0.73 & 0.03 & 0.04 & $0.58-0.88$ \\
Uric acid (mg/dL) & 4.61 & 0.06 & $3.7-5.5$ & \\
\hline
\end{tabular}

Abbreviations: SR, within-run SD; ST, between-run SD.

*Analyte concentration was determined within $20 \%$ of the test sample target value (pooled mean) according to Clinical and Laboratory Standards Institute EP31-A-IR. 


\section{Journal of LABORATORY MEDICINE and QUALITY ASSURANCE}

Eun Jin Lee et al • Verification of Comparability of Laboratory Results

EP31-A-IR 지침에서 제시한 범위검정방법에 따라 동등성을 검정하였다. 검증방법은 아래에 기술하였다.

(1) 2015년 5월 한 달간 건강검진을 위해 방문한 성인 500 명의 일반화학검사 후 잔여 혈청을 무작위로 모아서 혼합 한 후 분주하여 $-70^{\circ} \mathrm{C}$ 에서 냉동 보관한 냉동 혼주 혈청을 MODULAR와 200FR 장비 간의 동등성 검증에 이용하였다. 이 혼주 혈청을 각 장비에서 매일 오전 2회 오후 2회 반복 측 정한 항목별 결과값을 활용하여, 17 가지 임상화학 검사항목 에 대해 2015년 6월부터 11월까지의 6개월간의 평균(mean), within-run SD (SR)와 between-run SD (ST)를 장비별로 계산하였다[2]. 그리고 두 장비의 통합평균 및 통합(pooled) $\mathrm{SR}$ 과 ST를 아래와 같은 식으로 계산하여 Table 1에 나타내었 다.

Pooled mean $=\left(\right.$ mean $_{1}+$ mean $\left._{2}\right) / 2$

Pooled $\mathrm{SR}=\left(\left[\mathrm{SR}_{1}{ }^{2}+\mathrm{SR}_{2}^{2}\right] / 2\right)^{1 / 2}$

Pooled $\mathrm{ST}=\left(\left[\mathrm{ST}_{1}^{2}+\mathrm{ST}_{2}^{2}\right] / 2\right)^{1 / 2}$

이때 두 장비 간 ST의 차이가 2배 이하일 경우에만 동등성 평가를 위해 범위검정방법을 이용할 수 있으므로[1] 장비 간 $\mathrm{ST}$ 의 차이를 확인한다.
(2) 분석을 위한 검체는 (1)에서 구한 통합평균의 $\pm 20 \%$ 이내 농도를 가진 환자의 잔여 혈청 검체 또는 혼주 혈청으로 선정하였다. 동등성 검증을 위해 필요한 검체의 농도범위는 Table 1에 함께 제시하였다.

(3) 동등성 검증에 적용할 적합성 기준을 설정하였다. 검증 대상인 17개 항목에 대한 생물학적 변이계수(within-subject biological variability, $\mathrm{CV}_{\mathrm{I}}$ ) 등 고려할 수 있는 적합성 기준들 을 Table 2에 제시하였다. CLSI 지침에 따르면 전문가로서 평 가자의 의학적 판단에 따라 다양한 적합성 기준을 선택할 수 있다[1]. 이에 본 연구에서는 임상적 중요성 및 항목별 평균 측 정치와 6 개월 동안 두 대의 장비 간의 결과의 치우침, 바이어 스를 종합적으로 고려하여 각각의 적합성 기준을 선정하였다. 선택된 적합성 기준을 토대로 동등성 검증에 적용할 임계 차이 (critical difference, $\mathrm{CD}$ )를 아래와 같은 식으로 계산하였다.

$\mathrm{CD}=$ initial measured value $\times$ selected acceptance criteria

(4) 범위거절 한계에 대한 CLSI EP31-A-IR의 부록(appendix) $\mathrm{B}$ 에 제시된 표(tables of range rejection limit)를 사용 하여 항목별로 범위거절 한계 값과 측정반복 횟수(number of replicates)를 결정한다. 이 표에서는 측정 횟수(run)가 1일

Table 2. Multiple acceptance criteria that can be applied to the comparability test

\begin{tabular}{|c|c|c|c|c|c|c|c|}
\hline Parameters & $\mathrm{CV}_{\mathrm{I}}(\%)$ & $\mathrm{CV}_{\mathrm{G}}(\%)$ & I (\%) & B (\%) & $\mathrm{TE}(\%)$ & CLIA & $\begin{array}{l}\text { Selected } \\
\text { acceptance } \\
\text { criteria }\end{array}$ \\
\hline Albumin (g/dL) & 3.2 & 4.75 & 1.6 & 1.43 & 4.07 & $10 \%$ & $\mathrm{TE}$ \\
\hline Alkaline phosphatase (IU/L) & 6.45 & 26.1 & 3.23 & 6.72 & 12.04 & $30 \%$ & $0.33 \times \mathrm{CV}_{\mathrm{I}}$ \\
\hline Alanine transaminase (IU/L) & 19.4 & 41.6 & 9.7 & 11.48 & 27.48 & $20 \%$ & $\mathrm{TE}$ \\
\hline Aspartate aminotransferase (IU/L) & 12.3 & 23.1 & 6.15 & 6.54 & 16.69 & $20 \%$ & $\mathrm{TE}$ \\
\hline Calcium (mg/dL) & 2.1 & 2.5 & 1.05 & 0.82 & 2.55 & $1.0 \mathrm{mg} / \mathrm{dL}$ & CLIA \\
\hline Cholesterol (mg/dL) & 5.95 & 15.3 & 2.98 & 4.1 & 9.01 & $10 \%$ & $\mathrm{TE}$ \\
\hline Chloride (mg/dL) & 1.2 & 1.5 & 0.6 & 0.5 & 1.5 & $5 \%$ & $\mathrm{TE}$ \\
\hline Creatinine $(\mathrm{mg} / \mathrm{dL})$ & 5.95 & 14.7 & 2.98 & 3.96 & 8.87 & $15 \%$ & CLIA \\
\hline Direct bilirubin $(\mathrm{mg} / \mathrm{dL})$ & 36.8 & 43.2 & 18.4 & 14.2 & 44.5 & - & $\mathrm{TE}$ \\
\hline Gamma-glutamyltranspeptidase (IU/L) & 13.4 & 42.15 & 6.7 & 11.06 & 22.11 & - & $\mathrm{TE}$ \\
\hline Glucose $(\mathrm{mg} / \mathrm{dL})$ & 5.6 & 7.5 & 2.8 & 2.34 & 6.96 & $10 \%$ & $\mathrm{TE}$ \\
\hline Potassium (mg/dL) & 4.6 & 5.6 & 2.3 & 1.81 & 5.61 & $0.5 \mathrm{mmol} / \mathrm{L}$ & $\mathrm{TE}$ \\
\hline Lactate dehydrogenase (IU/L) & 8.6 & 14.7 & 4.3 & 4.3 & 11.4 & $20 \%$ & $\mathrm{TE}$ \\
\hline Sodium $(\mathrm{mg} / \mathrm{dL})$ & 0.6 & 0.7 & 0.3 & 0.23 & 0.73 & $4 \mathrm{mg} / \mathrm{dL}$ & CLIA \\
\hline Total protein $(\mathrm{mg} / \mathrm{dL})$ & 2.75 & 4.7 & 1.38 & 1.36 & 3.63 & $10 \%$ & CLIA \\
\hline Total bilirubin (mg/dL) & 21.8 & 28.4 & 10.9 & 8.95 & 26.94 & $0.4 \mathrm{mg} / \mathrm{dL}$ & $0.33 \times \mathrm{CV}_{\mathrm{I}}$ \\
\hline Uric acid (mg/dL) & 8.6 & 17.5 & 4.3 & 4.87 & 11.97 & $17 \%$ & $0.33 \times \mathrm{CV}_{\mathrm{I}}$ \\
\hline
\end{tabular}

Abbreviations: $\mathrm{CV}_{\mathrm{I}}$, within-subject biological variability; $\mathrm{CV}_{\mathrm{G}}$, between-subject biological variability; I, desirable specification for imprecision; $\mathrm{B}$, desirable specification for inaccuracy; TE, desirable specification for allowable total error; CLIA, Clinical Laboratory Improvement Amendments. 


\section{Journal of LABORATORY MEDICINE and QUALITY ASSURANCE}

Eun Jin Lee et al $\bullet$ Verification of Comparability of Laboratory Results

때와 2일 때에 각각 다른 측정반복 횟수를 제시하고 있는데, 측정 횟수가 1 일 때보다 2 일 때 더 적은 수의 측정반복 횟수로 도 동일한 통계적 검정능력을 갖는 점[1]을 고려하여 모든 항 목의 측정 횟수는 2 로 통일하였다.

(5) 두 장비를 이용하여 각각의 항목마다 결정된 반복 횟수 만큼 측정하여 결과 값의 평균을 구하고 장비 별 평균의 차이 를 이용하여 아래와 같이 범위를 구하였다.

Range $=$ maximum observed mean-minimum observed mean

(6) (5)에서 구한 범위 값이 (4)에서 설정한 범위거절 한계 값보다 작다면 두 장비 간의 동등성은 적합하다고 판정하였고 만약 범위 값이 범위거절 한계 값보다 크다면 분석적 문제가 있다고 확인하였다.

\section{결과}

\section{1. 적합성 기준의 선정}

본 연구에서는 임상적 중요성 및 검증항목 각각의 정도관리
데이터를 고려하여 항목별로 적절하게 적합성 기준을 선택하 였다. 17 개의 동등성 검사항목 모두에서 두 장비로부터 얻어진 $\mathrm{ST}$ 가 2배 이하의 차이를 보여 범위검정방법을 적용할 수 있 었다. CLSI에서 제시한 적합성 기준 중에서 Weastgard QC database [3]에 근거한 $\mathrm{CV}_{\mathrm{I}}$ 에 0.33을 곱한 값, Weastgard $\mathrm{QC}$ database의 총 오차(total error, $\mathrm{TE}$ ), 또는 Clinical Laboratory Improvement Amendments 지침[4]에 따른 기 준을 적합성 기준으로 조사하였으며 각 항목의 임상적 특성을 고려하여 이 중 한가지를 항목별로 선정하였다. 조사한 적합성 기준과 본 연구에서 선정한 기준을 Table 2 에 제시하였다.

\section{2. 적합성 평가결과}

범위검정의 시행결과 17 개의 검사항목 중 16 개의 항목에서 범위거절 한계 값보다 두 장비의 측정값 평균의 차이가 작게 나타나 장비 간 측정결과의 동등성이 있는 것으로 평가되었다. 그러나 크레아티닌에서는 CLSI EP31-A-IR 지침에 따른 범 위검정을 시행할 수 없었는데, Table 2의 여러 적합성 기준 중 어떠한 기준을 선택하여도 측정반복 횟수 및 범위거절 한계 값

Table 3. Results of the range test for the comparability test

\begin{tabular}{|c|c|c|c|c|c|c|c|}
\hline Parameters & $\begin{array}{l}\text { Level of } \\
\text { analyte }\end{array}$ & $\mathrm{CD} / \mathrm{ST}$ & $\mathrm{SR} / \mathrm{ST}$ & $\operatorname{Run}(\mathrm{N})$ & $\begin{array}{c}\text { Replication } \\
\text { (N) }\end{array}$ & $\begin{array}{l}\text { Range } \\
\text { rejection } \\
\text { limit }\end{array}$ & $\begin{array}{c}\text { Range test } \\
\text { (mean A-mean B) }\end{array}$ \\
\hline Albumin (g/dL) & 4.8 & 2.62 & 0.78 & 2 & 2 & 0.13 & $0.08=4.67-4.59$ \\
\hline Alkaline phosphatase (IU/L) & 63 & 1.35 & 0.88 & 2 & 5 & 0.94 & $0.7=62.3-61.6$ \\
\hline Alanine transaminase (IU/L) & 14 & 6.13 & 0.77 & 2 & 1 & 1.89 & $0=14-14$ \\
\hline Aspartate aminotransferase (IU/L) & 22 & 2.83 & 0.71 & 2 & 2 & 2.53 & $1.2=24.8-23.6$ \\
\hline Calcium (mg/dL) & 10.1 & 6.43 & 0.73 & 2 & 1 & 0.49 & $0.16=9.66-9.5$ \\
\hline Cholesterol (mg/dL) & 179 & 5.77 & 0.8 & 2 & 1 & 7.9 & $2=172-170$ \\
\hline Chloride (mg/dL) & 103 & 1.91 & 0.9 & 2 & 4 & 1.04 & $0.25=103.63-103.38$ \\
\hline Creatinine (mg/dL) & 0.82 & 1.47 & 0.3 & $\mathrm{NA}^{*}$ & $\mathrm{NA}^{*}$ & $\mathrm{NA}^{*}$ & $\mathrm{NA}^{*}$ \\
\hline Direct bilirubin (mg/dL) & 0.2 & 5.96 & 0.67 & 2 & 1 & 0.04 & $0.03=0.20-0.23$ \\
\hline Gamma-glutamyltranspeptidase (IU/L) & 19 & 3.1 & 0.6 & 2 & 1 & 2.77 & $1=20-19$ \\
\hline Glucose (mg/dL) & 96 & 4.70 & 0.83 & 2 & 1 & 3.27 & $2=93-91$ \\
\hline Potassium (mg/dL) & 4.4 & 5.03 & 0.82 & 2 & 1 & 0.12 & $0.05=4.45-4.40$ \\
\hline Lactate dehydrogenase (IU/L) & 306 & 2.67 & 0.75 & 2 & 2 & 23.36 & $4.5=299.0-294.5$ \\
\hline Sodium (mg/dL) & 144 & 4.48 & 0.82 & 2 & 1 & 1.96 & $1=143-142$ \\
\hline Total protein $(\mathrm{mg} / \mathrm{dL})$ & 7.5 & 1.56 & 0.38 & 2 & 1 & 0.37 & $0.1=5.5-5.4$ \\
\hline Total bilirubin (mg/dL) & 0.76 & 1.54 & 0.89 & 2 & 8 & 0.04 & $0.01=0.74-0.73$ \\
\hline Uric acid (mg/dL) & 4.7 & 2.12 & 1.01 & 2 & 2 & 0.09 & $0.05=4.68-4.63$ \\
\hline
\end{tabular}

If the calculated ranges are less than or equal to the range rejection limit, the comparability of the methods is acceptable. Abbreviations: CD, critical difference; ST, between-run SD; SR, within-run SD; NA, not available.

${ }^{*}$ Comparability testing for creatinine was not applicable because the appropriate replication number and range rejection limit were not obtainable from the table of range rejection limits in Clinical and Laboratory Standards Institute EP31-A-IR. 


\section{Journal of LABORATORY MEDICINE and QUALITY ASSURANCE}

Eun Jin Lee et al $\bullet$ Verification of Comparability of Laboratory Results

이 CLSI 지침에서 제공하는 표에 제시되지 않았기 때문이었 다. 항목별 범위검증 시행결과는 Table 3에, 알칼리인산분해 효소의 예시로 살펴본 범위 검증절차와 검증결과를 Fig. 1에 나타내었다.

\section{고찰}

여러 대의 장비로 측정한 검사항목에 대하여 동일성이 검증 되지 않은 결과를 보고하는 것은 진단 및 치료에 혼선을 주어 임상적으로 중대한 영향을 미칠 수 있다. 따라서 대한진단검사

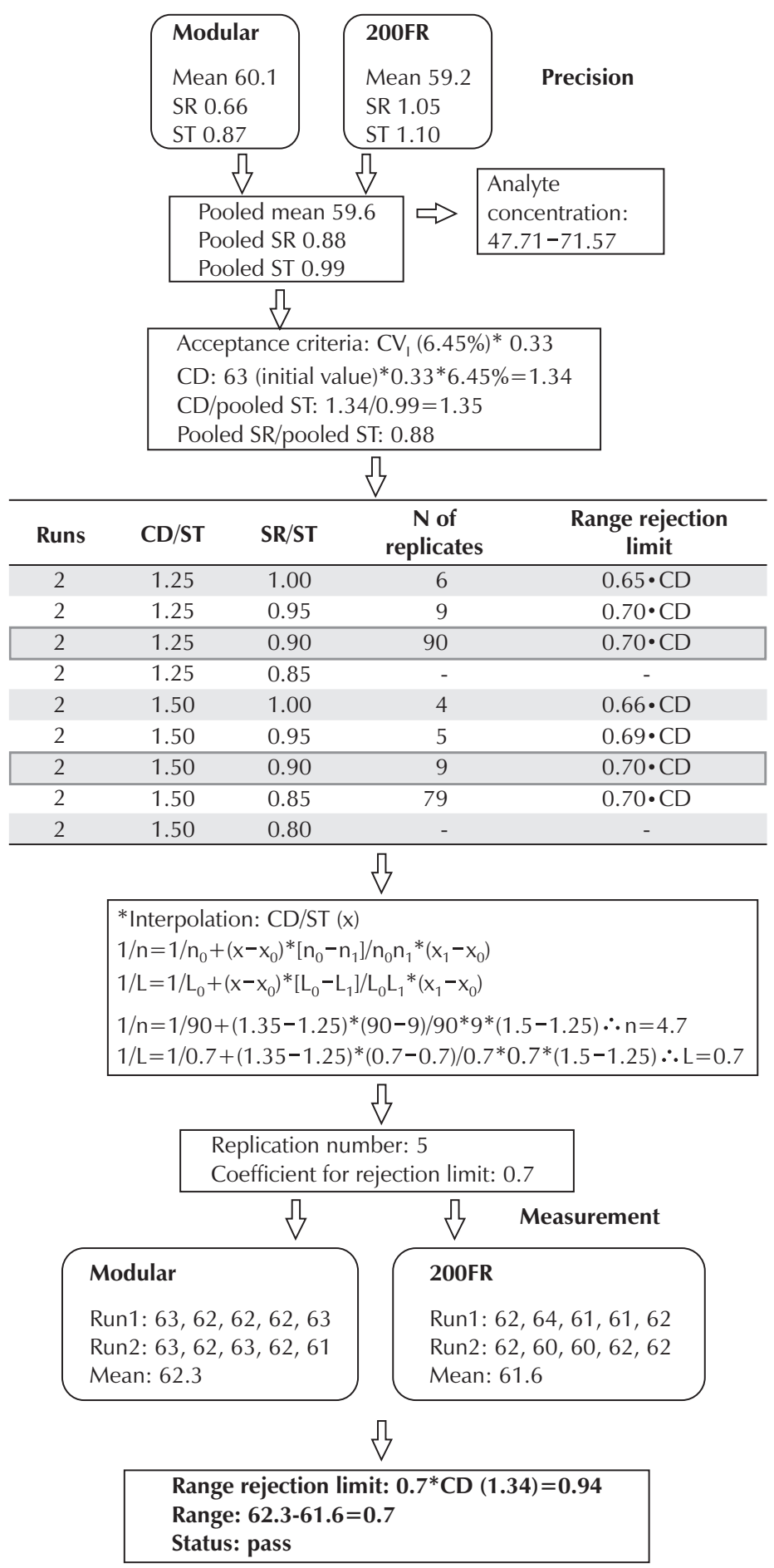

CLSI EP31-A-IR Appendix B.
Fig. 1. One example of the procedure used for verifying comparability: alkaline phosphatase. Abbreviations: SR, withinrun $\mathrm{SD}$; $\mathrm{ST}$, between-run $\mathrm{SD}$; $\mathrm{CD}$, critical difference; $\mathrm{CV}_{\mathrm{I}}$, within-subject biological variability. 


\section{Journal of LABORATORY MEDICINE and QUALITY ASSURANCE}

\section{Eun Jin Lee et al • Verification of Comparability of Laboratory Results}

의학회와 진단검사의학재단의 우수검사실 신임인증평가에서 는 동일검사항목에 대하여 서로 다른 두 대 이상의 장비로 검 사를 시행하는 경우, 각 장비 간 일치도에 대한 기준 설정 여부 와 6개월마다 검사결과 간 비교를 실시하는지를 평가항목으로 두고 있다[5]. CLSI에서 제시하는 동등성을 평가하는 지침을 이용하면 임상검사실에서 정도관리 데이터를 이용하여 간편 하게 검사결과 간 일치도를 평가할 수 있다.

Kim과 Cha [6]는 CLSI EP31-A-IR의 이전 버전인 C54-A 를 토대로 두 대의 동일한 장비에서 측정되는 결과의 동등성을 검증하였고, 그 결과 평가항목 모두에서 두 장비 간의 동등성 을 보였다고 보고하였다. 그러나 이렇게 동일 제조사의 장비로 진행한 동등성 검증은 다른 제조사의 장비를 이용하고 있는 검 사실의 검증과 그 결과에 차이가 있을 수 있다. 실제 임상검사 실에서는 서로 다른 제조사의 장비를 사용하는 경우가 흔한데, 본 연구는 서로 다른 제조사의 장비를 대상으로 동등성을 검증 한 경우이다. 이에 본 연구에서 제시한 서로 다른 두 장비 간의 동등성 검증 경험은 다양한 임상검사실에서 동등성 검증에 실 제적으로 유용한 도움을 줄 수 있을 것으로 생각한다.

CLSI 지침에 따른 검증결과를 살펴보면, 본 검사실에서 이 용 중인 두 장비 간 임상화학 검사항목은 동등성이 대체로 잘 유지되고 있는 것으로 나타났다. 그러나 검사항목 중 CLSI 지 침으로 평가할 수 없는 항목이 존재하였다. 이러한 항목의 경 우 최소 20 개 이상의 다양한 농도를 가진 검체를 이용해 선형 회귀분석 등의 다른 통계적 기법을 이용한 바이어스 분석방법 을 통해서 검증 가능하다[2,7,8]. EP31-A-IR 지침은 범위검 정방법 외에 다른 동등성 검증절차를 각 검사실에서 개발하여 사용할 수 있으며, CLSI의 지침이 이를 배제하기 위함이 아님 을 언급하고 있다. 따라서 실제 임상검사실에서 동등성 검증을 시행할 때 본 연구의 경우처럼 EP31-A-IR 지침이 적용되지 않는 경우가 존재한다면 이 지침보다는 다소 복잡하겠지만 다 른 절차를 이용하는 것이 가능하다고 판단된다.

범위 검정방법에 따른 동등성 평가에서 적합성 판정기준은 검사결과의 동등성을 판정하는 데 결정적인 영향을 미칠 수 있다. CLSI 지침에서는 이 기준으로 잘 설계된 임상결과연구 (well-designed clinical outcome study), 임상의를 대상으로 한 설문조사, 생물학적 변이를 이용한 설정, 전문가집단에 의 해 출판된 추천지침이나 승인된 기관들에 의해 정해진 목표, 내부비정밀도데이터(internal imprecision data) 또는 외부 신빙도조사 데이터(external proficiency testing data)에 근 거한 일반적인 허용범위 등을 제시하고 있다. 추천되는 잘 설 계된 임상결과연구를 적용하는 방법으로 대표적인 항목에는 hemoglobin A1c가 있다[9]. 하지만 이러한 임상결과연구는
적용 가능한 항목이 매우 제한적이다. 다음으로는 임상의를 대 상으로 한 설문조사방법 등이 있으나 현실적으로 어려우며, 임 상의마다 다른 견해 차이가 존재하는 경우에는 객관적이지 않 을 수 있는 문제가 있다. 생물학적 변이에 의한 허용 가능 바이

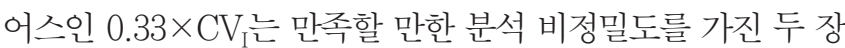
비에서 낸 차이가 개인에서 시간에 따라 보일 수 있는 결과 값 의 차이보다 작도록 목표하는 것이다. 그러나 개인 내 변동성 이 크지 않은 검사항목, 예컨대 전해질 농도나 단백 농도 등은 분석에서 포함하는 변이가 개인 내 변동성에 비하여 상대적으 로 커서 모든 항목에 이 기준을 적용하기에는 현실적으로 무리 가 있다[10]. 또한 EP31-A-IR에서 제시하는 범위검정을 수행 하기 위해서는 우선 $\mathrm{CD}$ 가 ST보다 커야 하는데 적합성 판정기 준을 $0.33 \times \mathrm{CV}_{\mathrm{I}}$ 로 정한 경우 많은 항목에서 $\mathrm{ST}$ 가 $\mathrm{CD}$ 보다 컸 다. 즉 장비의 분석능이 이러한 목표에 비하여 많이 부족하다 는 것을 보여주었다. 따라서 본 연구에서는 검사항목의 $\mathrm{CV}_{\mathrm{I}}$ 및 desirable TE, 실제 검사실 장비의 비정밀도 등을 참고하여 항 목별로 적합성 판정기준을 결정하였다. 이처럼 검증방법과 장 비에 따라 검사실마다 실정에 맞는 다른 기준이 선택될 수 있 을 것으로 생각한다.

이 연구에서 나타난 범위검정의 또 다른 한계는 $\mathrm{SR} / \mathrm{ST}$ 가 CLSI EP31-A-IR 부록 B의 표에서 제시된 SR/ST보다 훨씬 더 작으면 범위검정을 적용할 수 없다는 것이다. 크레아티닌의 경우 $\mathrm{CD} / \mathrm{ST}$ 값이 $1.47, \mathrm{SR} / \mathrm{ST}$ 가 0.3으로 CLSI EP31-A-IR 부록의 표에서 $\mathrm{CD} / \mathrm{ST}$ 값이 1.5 일 때 측정반복 횟수와 범위거 절 한계 값을 제시하고 있는 $\mathrm{SR} / \mathrm{ST}$ 최소값이 0.85 인 것에 비 해 상대적으로 매우 작은 SR/ST값을 보여 범위검정에 필요한 측정반복 횟수를 얻을 수 없었다. 본 검사실에서 크레아티닌 검사에 이용 중인 Jaffe 법은 시간의 흐름에 따라 색소 침착이 일어나 시약이 진해지는 간섭현상이 존재한다[11]. 이로 인해 within-run SD (pooled SR, 0.03) 값에 비해 between-run $\mathrm{SD}$ (pooled ST, 0.008) 값이 상대적으로 크다고 판단된다.

통계적 정도관리를 위해서는 해당 검사종목의 중요 임상적 판단범위가 포함되도록 2 가지 이상 농도의 정도관리물질을 사 용한다[12]. 본 연구는 CLSI EP31의 범위검정방법을 실제 검 사실의 결과에 적용해 봄으로써 해당 프로토콜이 임상적으로 유용하게 적용 가능한지 여부를 평가하고 문제점을 파악하는 것이 일차적인 목적이었으므로 연구의 편의를 위해 한가지 농 도의 검체만을 이용하였다. 그러나 실제 검사실에서 정도관리 를 목적으로 동등성 평가에 이 연구의 프로토콜을 적용하고자 할 때는 임상적 판단에 중요한 레벨에서 모두 동등성 평가를 하는 것이 바람직하겠고 그러려면 임상적 판단이 중요한 각 레 벨에서 각 장비의 SR과 ST 조사가 선행되어야 할 것으로 판단 


\section{Journal of LABORATORY MEDICINE and QUALITY ASSURANCE}

Eun Jin Lee et al $\bullet$ Verification of Comparability of Laboratory Results

된다. 현실적으로는 정도관리물질을 서로 다른 장비에서 공통 으로 사용한다면 쉽게 필요한 자료를 수집할 수 있으리라 여겨 진다.

결론적으로 CLSI EP31-A-IR 지침은 검사실의 정도관리 데 이터를 동등성 검증에 활용할 수 있고 비교적 간편한 절차를 통해 동등성 정도를 평가 가능하여 임상적으로 유용하게 이용 될 수 있음을 확인하였다. 그러나 본 연구결과에서 나타난 대 로 CLSI EP31-A-IR 지침만으로 동등성 검증을 시행하는 과 정에는 검증이 불가능한 항목이 관찰되었으며 $\mathrm{CD}$ 값을 설정하 는 과정의 어려움도 존재하였다. 따라서 본 연구에서 제시한 동등성 검증과정의 예시를 참고하여 각 검사실에서는 실정에 맞는 동등성 검증방법을 고안하여 평가에 사용하는 것이 필요 하겠다.

\section{REFERENCES}

1. Clinical and Laboratory Standards Institute. Verification of comparability of patient results within one health care system: approved guideline (interim revision). EP31A-IR. Wayne (PA): Clinical and Laboratory Standards Institute, 2012.

2. Clinical and Laboratory Standards Institute. Evaluation of precision of quantitative measurement procedures: approved guideline. EP5-A3. Wayne (PA): Clinical and Laboratory Standards Institute, 2014.

3. Westgard JO. Desirable specifications for total error, imprecision, and bias, derived from intra- and interindividual biologic variation. http://www.westgard.com/ biodatabase1.htm (Accessed March 3, 2016).

4. Clinical Laboratory Improvement Amendments. Recommended total allowable error limits. http://wwwn. cdc.gov/clia/regs/subpart_i.aspx (Accessed March 3,
2016).

5. The Korean Society for Laboratory Medicine, Laboratory Medicine Foundation. Laboratory accreditation program checklist: clinical chemistry. Seoul: The Korean Society for Laboratory Medicine, 2012.

6. Kim BH, Cha YJ. Verification of comparability among quantitative results obtained using multiple instruments within a health care system. Lab Med Online 2014;4:6570.

7. Clinical and Laboratory Standards Institute. User verification of performance for precision and trueness: approved guideline. CLSI document EP15-A2. 2nd ed. Wayne (PA): Clinical and Laboratory Standards Institute, 2005.

8. Johnson R. Assessment of bias with emphasis on method comparison. Clin Biochem Rev 2008;29 Suppl 1:S37-42.

9. Larsen ML, Fraser CG, Petersen PH. A comparison of analytical goals for haemoglobin A1c assays derived using different strategies. Ann Clin Biochem 1991;28(Pt 3):2728.

10. Asberg A, Odsæter IH, Carlsen SM, Mikkelsen G. Using the likelihood ratio to evaluate allowable total error: an example with glycated hemoglobin (HbA1c). Clin Chem Lab Med 2015;53:1459-64.

11. Peake M, Whiting M. Measurement of serum creatinine: current status and future goals. Clin Biochem Rev 2006; 27:173-84.

12. Clinical and Laboratory Standards Institute. Statistical quality control for quantitative: measurement procedures: principles and definitions: approved guideline third edition. CLSI document C24-A3. Wayne (PA): Clinical and Laboratory Standards Institute, 2006. 
Clinical and Laboratory Standards Institute EP31-A$\mid R$ 에 따른 단일의료기관 내 두 대의 자동임상화학검사기기 간 결과 값의 동등성 검증

이은진 • 이은엽 • 김미영 • 김한성 • 이영경 • 강희정

한림대학교 의과대학 한림대학교성심병원 진단검사의학과

배경: 단일 임상 검사실에서 신속한 검사결과를 얻기 위해 여러 대의 검사장비를 이용하는 경우가 흔 하게 존재한다. 검사실은 이러한 검사결과 간의 동등성을 검증하여야 한다. 이 연구에서는 Clinical and Laboratory Standards Institute에서 제안한 동등성 검증 가이드라인인 EP31-A-IR을 이용하 여 두 대의 서로 다른 장비에서 도출되는 임상화학 검사결과의 동등성을 검증해보았다.

방법: EP31-A-IR 가이드라인에서 제시하는 범위검정방법을 이용하여 HITACHII/MODULAR system (Roche Diagnostics, Switzerland)과 TOSHIBA/200FR system (Toshiba Medical Systems Co., Japan)에서 도출되는 17가지 임상화학 검사결과의 동등성을 비교하였다.

결과: 생물학적 변동성에 0.33을 곱한 값, 총 오차, Clinical Laboratory Improvement Amendments 지침에 의한 기준을 임계차이 기준으로 선정하였다. 범위검정결과 검사항목 중 16 가 지 항목에서 두 장비 간 평균의 차가 범위거절 한계 값보다 작게 나타나 두 장비에서 도출된 결과에 동등성이 있는 것으로 확인되었다. 그러나 크레아티닌의 경우 EP31-A-IR 가이드라인에 제시된 표 를 이용하여 범위거절 한계 값을 구할 수 없어 평가가 불가능하였다.

결론: EP31-A-IR가이드라인은 다수의 검사기기에서 도출되는 임상화학 검사결과의 동등성을 평가 하는 데 유용하나 모든 항목을 이 가이드라인에 적용할 수 없었다. 각 검사실에서는 항목에 따른 특성 을 고려하여 검사실마다의 동등성 평가방법을 고안하여야 한다.

(J Lab Med Qual Assur 2016;38:129-136)

교신저자: 강희정

우)14068 경기도 안양시 동안구 관평로 170 번길 22, 한림대학교 의과대학 한림대학교성심병원 진단검사의학과 Tel: 031)380-3929, Fax: 031)380-3934, E-mail: kangheejung@hallym.ac.kr 